\title{
Social Experiment for Rural India: Addressing Indian Farmers Suicide Problems via Wireless Technology
}

\author{
Frank Lorne ${ }^{1}$, Roy Lai², Rimjhim Rosalin ${ }^{3}$, NikhilDnyandev Kurundvade ${ }^{3}$, Himanshu Ratra ${ }^{3}$ \\ ${ }^{1}$ Professor of Management, New York Institute of Technology-Vancouver \\ ${ }^{2}$ Chairman, Professor, Confederal Networks Inc. \\ ${ }^{3}$ MBA candidates, New York Institute of Technology-Vancouver. \\ Email: florne@nyit.edu
}

\begin{abstract}
India has a huge population, with $70 \%$ of the labor force engaged in agriculture. A social experiment is proposed in this paper for a focus study of the problem and the remedy for the Indian farmers suicide phenomenon. As a deep rooted problem in rural India, this paper suggests the need for bringing psychological consultation for the farmers, as suicide is an impulsive act that cannot be solely solved by long term infrastructure investment aiming for improvement of productivity and technology. The paper argues that the social experiment should be conducted in small scale in a remote rural setting as a small step, ideally by suitable NGOs, to more effectively isolate factors that contribute to the cause, as well as to experiment with more cost effective ways to provide remedies. Wireless technology provides the "in-the-moment" intervention for an impulsive act of selfdestruction. Although this intervention will not solve intermediate and long term infrastructure problems on the needs of farmers in rural India, it can be used as a spring board to promote other innovative initiatives of using wireless and digital technology. When farmers in primitive remote areas start using wireless technology and embrace the use of it as a habit, it will allow an easier integration with the many smart village initiatives already started and on-going in India. Promoting lifestyle is as important as promoting productivity. The social experiment will enhance sustainable development for India.
\end{abstract}

Keywords: India farmers suicide, telemedicine, NGO, wireless technologies for sustainable development

\section{$1 \quad$ Introduction}

In an era of industrialization, agriculture plays a pivotal role in strengthening the socio-economic scenario of the country. In an emerging country such as India, speedy rotation and good cultivation of crops are significant for economic successes. These factors have often been discussed in the realm of sustainable agricultural practices, better results in farming, and yielding more crops (National Research Council, 2010; Ciolos and Piebalgs, 2012; Cook, 2015).

Wireless technology for agricultural practices has also been explored in numerous studies (Kinkade and Verclas, 2008; Ferroni and Zhou, 2012; Vodafone Group, 2015; Sunding et al., 2016). It is commonly believed that embedding wireless technology in agricultural practices will enhance productivity and the changing of lifestyle among farming communities, spanning broad topics on health, humanitarian assistance, and environmental conservation. To equip peasants with good technology is generally a good idea. If implemented well, it will provide opportunities for backward communities to leapfrog to a better life, enabling a more balanced growth pattern in the industrialization process of emerging countries, typically characterized by over urbanization. Wireless technology can enhance sustainable development in emerging economies.

This paper focuses on a unique social problem which is prevailing among Indian farmers - the Indian farmer suicide problem. This problem has been recognized for a long time since mid-1990s, and much has been written about its causes (Mishra, 2007; Stone, 2007; Meghna, 2010; Rukminis, 2015). There have been numerous government and social attempts to address the problem, including some states wanting to implement a "zero-suicide" plan. Yet, the problem seems to persist. BBC News on May 24, 
2015 quoted Prime Minister, Narendra Modi, "The problem is old, deep-rooted and widespread and we have to seek solutions in that context." Also, most recently reported in 2016 in an India newspaper, nine farmers commit suicide daily in India. The report says:"3,228 farmers committed suicide in Maharashtra in 2015, the highest since 2001, according to data tabled in Rajya Sabha on March 4, 2016, "The top five major causes of farmer suicides in 2014 were bankruptcy or indebtedness $(1,163)$, family problems $(1,135)$, farming-related issues (969) - such as failure of crops, distress due to natural calamities, inability to sell produce, illness (745) and drug abuse and/alcoholic addiction (250). "” (Mid.Day. April 6, 2016; Mallapur, 2016).

Unquestionably, farmers' suicide problems can be triggered by various uncontrollable events such as natural drought. Yet, economic suffering cannot be the main cause leading a person to end his life in a deliberate self-destructive way, i.e. suicide. The act of committing a suicide can be impulsive, appearing in a spur of the moment when he/she is in despair with no one to turn to. This behaviour is psychiatric. Many in-house or online services such as Online Therapy USER for suicide resources do not provide emergency or crisis response service. The only means to revert to a live person when a person is alone with an immediate suicide decision is a cell phone, if the person is still open to some communication. Yet, as many studies have shown, suicide rarely occurs in a person who is not currently going through a depressive episode (Murphy, 1983; Joiner, 2005; Kleespies, et al., 2011; Fassberg, et al., 2012). Booth, et al., 2000, studied farmer suicide problem in England and Wales, and observed that the act of suicide did not occur abruptly either. The problem is also sociological in that it can arise from a lack of social integration (Radhakrishnan and Andrade, 2012). Thus, there is a gestation stage of the very act of suicide that can be managed. That should be the focus, independent of other social measures that can be brought along to improve farmers' lifestyle and living standards, improving productivity, etc., which have more to do with a long run solution of improving rural infrastructure.

Managing the mental health of Indian farmers who are prone to suicide should be the focus of the suicide problem of farmers. This problem cannot be solved by improving productivity and lifestyle alone. According to a recent study by the Indian government, there is only one psychiatrist per 400,000 people, and 37 mental institutions in a population of approximately 1.2 billion (Kennedy, 2010). People with psychotic disorders and acute depression problems may remain untreated for a long time. Faith healers, "evil magic" have been the more socially acceptable ways for curing mental illness in India in the past, but apparently not effective yet in dealing with this problem. There is now a strong case for policy initiatives to address public health and livelihood concerns of Indian farmers (Mishra, 2014). It urges development discourse linked to farmers' suicides to move away from a techno-centric yield or income focus to a people-centric livelihood and quality of life focus that is sustainable. Social consultation and psychiatric aid to the farmers are important to curb this deep-rooted problem with immediate timely intervention being the key to an impulsive act that can be avoided or delayed. It is in this sense that a wireless technology communication can take its role as an urgent relief of psychiatric tension. Telemedicine is beginning to venture into this direction, but it is still at its nascent stage of development. That is why we propose this as a social experiment, to be implemented in remote area resembling a controlled laboratory condition.

The need for a controlled environment is necessary for evaluating the cause as well as remedy to the suicide problems. In big cities, although wireless technology is more widely available, and thus telemedicine in the form of psychiatric consultation can be more easily implemented, it has other factors that interfere with the effectiveness of the particular psychiatric remedy to be experimented. Since telehealth is an evolving health management discipline that is still going through experimentation without a clear methodology (Marasinghe, et al., 2012; Hollis, et al., 2015), what work and what won't work require a more controlled environment to evaluate. Remote areas, by contrast, have less interference of multiple social factors associated with big cities. Thus, farmers with innate psychiatric consultation needs in more remote isolated areas are more likely to leapfrog using the intervention of wireless technology.

Reasons cited for farmer suicide have often been studied broadly without focusing on its psychological dimensions. Intellectual motivation can be incorporated into a practical remedy to achieve at a more general understanding of the farmer suicide problem in India. For example, the building of trust in a wireless communication mode would also allow the monitoring of socio-economic characteristics of individuals prone to suicide. If suicide problem is universal, it would not matter whether the social 
experiment is conducted in a remote area or in an area where the problem is most acute. The psychology of a person can be characterized equally in rural as much as in urban areas.

Last but not least, suicide prone farmers are unlikely to be the potential clients of high paid professionals as they are too poor to afford these types of services. Indeed, some have argued that farmer suicide problems were caused by profit incentives - perhaps by developers who are more interested in the land used by the farmers rather than the well beings of the farmers, or perhaps by external forces such as WTO, etc. (Stone, 2007; Shiva and Jalees, (n.d.)). ${ }^{1}$ Neither can government direct intervention be used as an effective solution for the problems, as implementation of such social programs are likely to run into typical inefficiency in implementation, with predictable effects on additional burden on social welfare programs administered by a government. Thus, the implementation of a wireless psychiatric consultation services may be best operated by a non-profit focused NGO. The efficient structure of such NGO in the context of a principal-agent problem needs to be addressed.

\section{Reasons and Methods for Using Wireless for the Farmer Suicide Problem}

Harnessing wireless technologies could be a way to address the mental health issue of Indian farmers. Generally, it is more difficult for the rural peoples in India to have access to psychiatric facilities. Wireless Technology could be the kingpin in addressing methods in providing a remedy in this direction. Bringing in telehealth services, mental health consultation groups, broadcasting radio programmes in rural areas to nourish farmers' mental health can break the orthodox (possibly idiosyncratic) beliefs prevailing among them and broaden their line of sight towards technology. Yet, wireless being the fastest and effective medium, one would think a large scale implementation of some technical wireless set-up countrywide especially in the context of big data will be a natural first step (Goli, et al., 2011; Carbonell, 2016). However, there are reasons to believe that implementing that in the remote rural villages as a first step in exploring remedies to the problem can be more effective.

In a recent smart village initiative for India, Prof. Darwin of Berkeley suggested a "small is smart" proposition: "making 6.5-lakh villages in India even 'slightly smart' would have an exponential impact on GDP and the Happiness Index.... Over 70 per cent of India's population lives in the villages and it does not take much technology to make villagers happy." (The Hindu, June 10, 2016). In addition, for the wireless social experiment addressing to suicide problems, there can be other reasons for making the experiment conducted for small scale in rural areas.

First of all, the causes of suicide can be multi-dimensional. The more complicated is the environment where a person is living in (e.g. a metropolitan city), the more factors must be considered. According to Radhakrishnan and Andrade, 2012, "The suicide rate is generally reported to be higher in urban areas because of a variety of stressors related to living and working in cities, including overcrowding and social isolation." Similar findings were reported in McCarthy, et al., 2012. Large cities also have more alternatives for reliefs and for suicide-prone victims to for choosing activities that will dilute attention of death being a solution to problems. Suicide problems in rural areas can be complicated by a reporting problem too: "The process of registering a death is particularly inefficient in rural areas. Eventually, only about $25 \%$ of deaths are registered and only about $10 \%$ are medically certified" (Radhakrishnan and Andrade, 2012). The data reliability problem alone would suggest that a first-step remedy to the problem should focus on rural areas, perhaps to ascertain whether the problem is under or over reported; in other words, to ascertain whether it is a real or an exaggerated problem. Thus, the social experiment cannot be implemented in an urban area, even though it has many other dimensions of social aids that can be bundled for more extensive implementation in high density areas.

Secondly, a social experiment is different from the testing of a hypothesis. There is a discovery process embedded in a social experiment that is different from an endeavor for collection of data, demographics, socio-economic variables which may have a bigger data pool in urban areas. The follow-up proactive social/psychiatric interaction with potential victims would be particularly essential. For example, let's

${ }^{1}$ Dr. Shiva, an environmental activist and anti-globalization author, found a movement called Navdanya, advocating earth democracy. A related publication on farmer suicide problems, Seeds of Suicide was published in 1998, with a Fourth revised edition in 2006. 
suppose the proposed intervention of a particular NGO implementing a social program rely largely on a spiritual religious method. The proven success of a particular methodology requires documentation, reporting, and distribution of results so that experience in the first step can be studied and further modified for a larger scale implementation (See example of Digital Green in Section III). Starting small is usually more manageable, and if effective, can be made scalable as a second step.

Thirdly, there is a transaction cost of setting up a social experiment. The bigger is the scale of an experiment, the more difficult it will be to set up initially. This aspect of the transaction cost must be added to the technological costs of running a program. More concretely, a social experiment in big metropolitan area would require heavy advertising costs, perhaps only the government can afford to implement. The advertising costs in rural community can be more effective, particularly if there is some unique element in it that allows the leapfrogging in that community. The word-of-mouth will spread the credibility of a program that can reach a threshold participation for achieving demonstrative impact.

Fourthly, the telemedicine industry outside India is still at its infancy; as such, it leaves plenty of opportunity for cross-culture, cross-country studies in telemedicine psychiatry methodology. Groups outside India are unlikely to participate in an Indian initiative applied broad scale countrywide, as it will be too big and too risky a project for any specific group to pick up, especially if the methodology of an approach is still at its infancy.

Social problems cannot be resolved with economic aid alone. Spreading awareness among the farmers, giving credible platform for their social interactions and connecting them to the agricultural expert across the globe can be a more focused solution to the farmer suicide problem. The remedy should enhance their lifestyle and crop yield, and should keep them updated with current trends, practices, and innovation implemented across the globe. Wireless medium could be particularly effective in this regard. Having an updated knowledge and instant response, assurance and resolving techniques in agriculture will help the farmers significantly to stay motivated; eventually lessening the suicide rates among Indian farmers.

There are several directions on how the social experiment can be designed for rural Indian farmers: A. Mental health Consultation- Telemedicine is an emerging field, using it to boost up the confidence level of farmers from time to time; taking an initiative to know their needs, knowing the knowledge gap which is prevailing; could be a powerful tool in addressing the social issue of farmer's suicide in rural India, (Barua, 2009). It is important to emphasize that suicide is an impulsive action, and all the technical activities to combat this mental health issue have to be implemented and practiced in a timely manner. Otherwise, it will not see result. As the proverb goes, "Timely help is the best help".

More specifically, the following development direction should be placed with high priority:

1. Telemedicine and psychiatric consultation for farmers:

In the past, some spiritual angle has been attempted to address the problem. For example, NGO such as M.A.M (Mata Amritanandamayi Math) in India has long addressed to his problem since 2000, drawing attentions of government representatives as well as other NGOs to the issue of the escalating rate of suicide among farmers. Efforts continued as one can see from their website as far along as 2008. Yet, a more scientific holistic approach still needs to be found.

Telemedicine is an emerging sector, where harnessing technology to provide mental health care to the farmers located at remote places in India could be effective. ${ }^{2}$ Providing care from a distance with a centralized platform for the farmers by connecting with psychiatric specialists is a unique aspect of telemedicine. There may be specific groups in the West where telepsychiatric cares are beginning to take on some specific methodologies, e.g. E-health Conference, July 31st, 2014; Hoffman, 2015, Evans and

${ }^{2}$ Telementalheatlh in the West, theoretically, can be traced back to 1953 when "The Samaritans Service" began offering telephone counseling for those in emotional distress in the United Kingdom and Ireland. The first U.S. suicide prevention telephone service "Call Bruce", originated in San Francisco in 1963 to provide accessible telephone interventions for those patients experiencing a "suicidal crisis". See this, and also some legal challenges of implementing such system in the US, Godleski, et al. 2008. An undated study by a group at The University of Texas Medical Branch (UTMB Health) documented some early use of mobile and wireless platforms in health care in Texas. 
Narasimhan, 2016. While the field is growing with great potentials, it was also pointed out specifically in one of the studies that "many mobile mental health apps exist, but few have had the benefit of rigorous evaluation." Telemedicine could bridge the gap in providing timely crucial care which is important for a farmer who is undergoing distress for a while and is impulsive to commit suicide. M.A.M. has recent development in the field of telemedicine, the professional psychiatric component of the program can perhaps be included as development in this direction is progressed in India. ${ }^{3}$

There can be several positive outcomes by harnessing this treatment:

a. It centralizes the farmers and the mental health specialists (potentially combining an East and West approach) and provides farmers with a wide connectivity and access of technology

b. This social experiment is cost effective and efficient, given the state of art in wireless technology

c. The cause of impulsive suicide urge of Indian farmers could be more scientifically understood, allowing a surgical penetration in exploring the root of the problems for Indian farmers suicide

The development of high speed wireless telecommunication network in these remote areas coupled with mobile communication accessibility, could pave the way for Telemedicine. This will yield a delivery of an efficient mental health care for the distressed farmers.

With a significant leap forward in technology and psychiatric care field as a spring board, it could also allow for the real time monitoring and interacting with the farmers, enabling the consultation team to understand them better generally, and hence provide them with best help.

With the potential results of the experiment we could weave a network of consultation groups in these remote areas, who can provide help to farmers in restoring their faith and trust in innovation in farming practices, preventing them in committing suicide in near future.

2. Extensions to other aspects of psychiatric care and the building of a more social live.

Integrating the idea of psychotherapy for Indian farmers (by training them for problem solving, brief meditation, enhancing their social support circle, advise on drugs/alcohol and other psychiatric problems via mobile devices (pocket friendly simple devices) with a mobile follow-up to know their progress updates.(NIMH, May 2016.) And this idea could be essentially merged with the "M-apps" (Hollis, et al., 2015) for farmers that have already been implemented to some extent in other areas in India (cite). This is a unique angle of an emerging field: Telemedicine. The development of mobile mental health interventions for patients who are diagnosed with schizophrenia should accommodate the cognitive needs of the farmers as well. This can all be integrated with a ground operation of small scale, informing the recent crop/cultivation news and other strategies while simultaneously addressing farmers' psychological needs.

B. Integration with regular radio programs that aim to achieve entertainment and the gaining of friendship

Human beings do not usually trust a stranger's advice. To induce farmers to treat their mobile device as a "friend" and not just something they will need in emergency, a regular program of some type needs to be implemented also. This could be entertainment or religion based. The mission of this station is to provide edu-entertainment for farming communities. This could be a combination of music, lectures, perhaps done simplistically by syndicating existing programs from major cities. Naturally, chosen target groups, brand positioning, music cuts, jock personalities, etc. all come to play in having an effective radio programme. The India broadcast authority is likely to assign radio frequency if the station can show their programs paying special attention to the field of education and spread of literacy, agriculture, rural development, environment, health and family welfare, as well as science and technology, e.g. See Mane,2013.

The concept of community radio is now quite common in India (Frederick, 1998). Good radio programmes not only can enhance faith and nurture a bright outlook of life in Indian farmers, de-rooting "death as a solution", it can inculcate the power of information and use of wireless technology for them. It can include participatory communication approach as has been experimented in other rural communities of the world (Chapman, et al., 2003). Empowering rural farmers about their own potential in getting back their own life in their control and laying a strong pitch for the future should be the central notion of a suitable radio programme.

${ }^{3}$ http://amma.org/telemedicine-amrita-institute-medical-sciences 
The psychological diseases are related to the mental adaptability of a person. Patients suffer from a type of psychotic impulsiveness that could be specific to certain cultures: they get only if they believe in them. ${ }^{4}$ Good radio programmes addressing such health ailments could be promoted. Building faith in Indian farmers; inculcating in them the power of information and wireless technology, de-rooting the "fear of death" in them are few of the targeted goals of the radio programmes. Trained mental health care personnel, care and treatment facilities, should be made available to rural farmers and voluntary organisations can be encouraged to participate in it (Barua, 2009). The deliverables need to be entertaining, vernacular, and habitual in order to lure farmers into treating the gadget introduced as their true companion. Listening to a radio programme should not be a chore, but a bliss.

\section{Effective NGO for Implementing Social Experiment}

We now approach a crucial question: Who will be financing the social experiment, and what is the governance structure necessary to implement it? Ferroni and Zhou, 2012, described a large variety of how this could be done, providing a useful framework on how a farmers-centered institutional structure can be designed. Our section here brings up some additional elements for consideration, starting with an introspection of some basic questions. The first part of the question just raised has to do with social justice, and as such, the role of government is unavoidable. The second part of the question is a classic principal-agent problem that every emerging economy must face. The principal in this case is the group of farmers, and the agents are experts, consultants, psychiatrists, social workers who need to have the welfare of the farmers at heart. The expert opinion cannot come about easily, as the incentive structure must be aligned for effective implementation. Surely, one can argue that this is a role that the government should take. However, incentive alignment is probably the worst for bureaucrats who may be working under a government's directives. For emerging countries, this method of funding and implementation breeds inefficiency and corruption.

The problem here is that the farmers are poor; and worse still, not knowing what they want or how to improve lifestyle. The implementation task therefore falls acutely on experienced professionals, who may or may not want to offer their professional hours, even if it is for a good cause. The principal-agent problem here is one of a peculiar one. The distribution of asymmetric information tilted towards the principal rather than the agent, as the principal does not know what he/she really wants, and must rely on experts to tell them what is good for them. This problem is similar to one that was tackled in a previous study by one of the authors of this article for ARV drug dissemination in poor countries (Lorne and Shah, 2015). The study found that in poor countries, a face-to-face, one-on-one sales interaction (small scale) can sometimes be more informative and persuasive than large scale purchase resulting from advertising or direct implementation from the headquarters of powerful drug manufacturers. Thus, the role of an NGO (Non-government organization) is predictably instrumental and crucial in the implementation of social experiment of this kind.

Governance for NGO has been studied. Peterson, 2010, recognized a governance issue between funding source and agencies implementing the funding objectives of a foundation or a corporation with missions for social responsibility. Failure of NGO agents to perform required tasks can reach $75 \%$ or higher. An institutional design that can help curb the asymmetric information problem for this type of a principalagent problem is particularly acute. He summarized NGO governance issues into two categories of questions: Agency theory and the building of trust. This approach was similarly echoed in Lorne and Shah, 2015. In that respect, theoretical and practical features of NGO that need to be curbed or promoted can also be found in Orffmand and Schlessenger, 1997; Das and Teng, 1998; Yanacopulos, 2005 .

NGO dealing with Indian farmer suicide problem is not without precedent. But in the past, such remedies have been geared mostly toward economic measures, which address to infrastructure enhancement to improve lifestyle and reduce suicide problem in the long run. However, if suicide problem is time-urgency sensitive, an infrastructure needs to be set up specifically for a psychiatric intervention in a timely manner. There is a spiritual based NGO that has addressed farmers' suicide problem as early as in 2000. Mata Amritanandamayi Math (MAM), with the establishment of Amrita-

${ }^{4}$ The Atlantic, April 22, 2016. 
ISRO Village Resource Centers, together with a university, health services, etc. that, according to their website, offered some type of a farmer suicide remedy for at least 8 years or so. However, it is not clear whether professional psychiatric remedies were used.

The social experiment proposed in this paper must start from sketches, utilizing telemedicine techniques in the West and perhaps involving western psychiatric consultant for human resources training. A fresh managerial knowledge and talent needs to be cultivated specifically for this. A funding source (most likely from the West), affiliated with the telemedicine-psychiatric movement of in North America, needs to take a leading funding drive in this regard, as this institutional set-up would better align incentives, much like how drug manufacturers in the West has an incentive to provide AVR drugs to poor countries, for profit as well as humanitarian reasons.

There is a difference between this social experiment and that conducted for AVR drugs dissemination, however. The AVR drug production has scale economies in production that in principle, drugs can be provided extensively in large quantities to a country as large as India. No such presumption can be made for professional services. These are intrinsically small scale, and are intended to be provided as a win-win proposition to a rural farming community - for the benefit of the rural farmers on the one hand, and for reaffirming some nascent telemedicine-psychiatric methodology invented in the West on the other.

The NGO role in bargaining down the drug price is not present for this experiment. The agency problem should focus on how the expert professionals can work with field officers. The organization format entails putting field officers from qualified NGO to work with professionals designated by the funding source in mapping out a training, reporting, and interactive structure to run this experiment. The details of this proposal have yet to be spelled out, but the discussion in this paper has pointed out a possibility of an incentive alignment that will be crucial for implementing a social experiment.

According to Ferroni and Zhou, 2012, there were already 282,000 input dealers in India, and this number is expected to grow. These core of middlemen can rely to some extent training provided by the government, but can also self-select in an evolutionary manner in arriving in a nucleus with a mission. ${ }^{5}$ In the US, NGOs such as the American Foundation for Suicide Prevention (AFSP) initially were formed by a small group of caring individuals who had a vision. The founding families - each of whom had lost someone in their family -joined with scientists to create the organization. The Indian farmers suicide problem is drawing national and international attentions. We therefore expect it's a matter of time that similar organizations will arise in India.

Undoubtedly, the NGO that will take up this responsibility must understand community development (World Bank, 1992). There are also other world organizations that specifically teach NGO to be community builders. For example, Global Communities have long established methodologies for this purpose with practicalsteps: 1. Start off with a transparent community selection process and share results, 2. Map community priorities and identify community leaders through community assessments, 3 . Hold preliminary meetings with community leaders and enlist their support to mobilize community participation, 4. Hold community assembly meetings to elect local representation to coordinate program activities, perhaps the forming of theme clubs at the grassroots level, 5. Allow communities to prioritize and select quick impact projects to solidify support and galvanize local participation. Funding source should select NGOs that have demonstrated track records in the past in community development as the most important criteria for funding.

Addressing to incentive alignment suggests that perhaps other domestic NGO funding source might also be involved. As long as the social experiment can accommodate implementation of missions of other NGOs, there are no reasons why such NGOs would not be interested in becoming part of a funding alliance. Projects of this type may be too small for NGOs such as Basix, PRADAN, and BAIF, but everything starts small. The process of gaining recognition by a NGO in an incentive compatible manner is the focus of interest here for contemplation.

There is much to learn from the success of an NGO, big or small, as it is the process of how an NGO can achieve incentive compatibility that will be of interest. For example, Digital Green, a web-based video production company with a mission of disseminating rural agriculture success methods and stories, found partnerships with various digital technology companies in the West to make India village smart.

${ }^{5}$ For example, a group called Milaap had a fundraising event on the internet in July 2015, raising Rs1,107,343, reporting that the full amount being sent to "Kishore Tiwaariji" as of July 26, 2016. 
In 2009, Green digital received a funding of $\$ 2.3$ million from the Gates Foundation. They have also received USD $\$ 2.15$ million from Google's "Impact Challenge in India”. It is Digital Green's success in recruiting commercial partners on the one hand, and its ability to install a ground work managerial organization and dissemination structure that made the NGO a great success. The attention of past success can add credibility and trust to new works they pick up, as their working scope expand with several NGO's in agri-business as well as the Ministry of Rural Development of India. Digital Green, as a coalition with its partners, strategically acts and reacts to changing resources in their environments. The list of partners that Digital Green was able to recruit as sponsors is indeed very impressive.

The ground work coordinated is also extremely important. According to the description on Digital Green's website, Digital Green utilizes village-level mediators, and development agents (DA), trained by them and the government to produce and share videos on locally relevant agronomic, health and livelihood practices. A community video production team of four to six individuals in each district creates videos. A facilitator from the community mediates a discussion around the video screenings by pausing, rewinding, asking questions, and responding to feedback. The ground work operation therefore is not complicated, and easily scalable. Small team always enables effective solutions for principal-agent problems.

A small scale social experiment is a precondition for demonstrating impact, which cannot be predefined. The selection of a field work NGO therefore must also require them to provide a reporting structure that their impact can be evaluated. That structure must be reasonably transparent, open, and possibly holacratic in that it relies on a self-reporting system to replace a tradition hierarchical management method. ${ }^{6}$ That institution feature can be found in Digital Green also, in terms of digital tools such as a COCO platform and additional features of Videokheti, Farmer book, and Wonder village game that can be found on their website. It is interesting to note that during the early experimental stage of Digital Green, before these more sophisticated reporting features were developed, research reports were generated in conjunction with the experiment. ${ }^{7}$

Digital Green is just an example to illustrate how successful NGO can be put together by addressing to incentive alignment in partnership, principal-agent problems of ground operation, and a governance structure that is transparent and scalable. An NGO coalition aiming for a psychiatric solution to the farmers' suicide problem should aim for similar achievement also, for establishing an intermediate goal, and some long term goals.

\section{Technologies and Cost Estimates}

The basic science of wireless technology is well known (Ugweje, 2004). A basic wireless communication network can be put together specifically for a social experiment of a small scale for a targeted area of a radius of $2 \mathrm{~km}$. The network can be made consist of a compact LTE-based wireless network system developed to provide voice, text, video, PTT (push to talk) and dispatch services for rural area.

The signal is to be broadcasted via satellite from a ground server that may or may not be placed in the targeted area. With an antenna illustrated, its signals can be broadcasted and received from various LTE devices. The power can be a solar power system, but it need not necessarily be so.

The basic components of this system can be schematically illustrated below:

\footnotetext{
${ }^{6}$ Adjective for the term Holacracy, which is a social technology or system of organizational governance developed to promote self-organizing teams rather than being vested in a management hierarchy. See https://en.wikipedia. org/wiki/Holacracy

${ }^{7}$ See Gandhi, et al., 2009, the conclusion in the report gave some early impact statement for the experiment.
} 

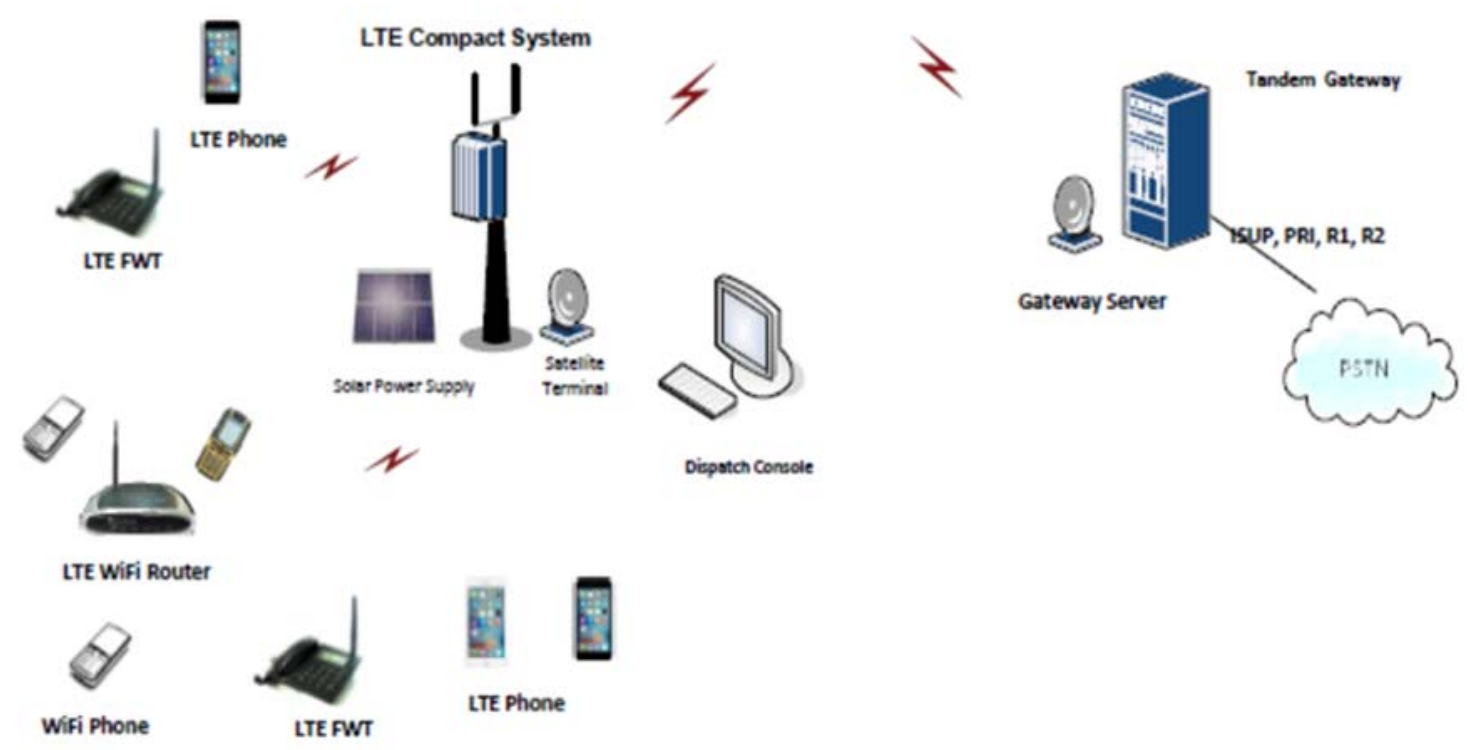

Source: Template provided by Cofederal Network Inc.., 2016.

The whole system consists of a compact LTE-based RAN, the outdoor passively cooled enclosure is about $20 \mathrm{Kg}$ which can be easily mounted on pole, roof, wall, or a tree. It integrates RAN (Radio Access Network) and call management functions, and can make phone calls without any additional component. The anticipated coverage is up to $5 \mathrm{~km}$ radius (which can be extended depending on antenna height and terrain). It supports 180 concurrent calls, and the voice call capacity is about 6,600 ( NoS=2\%).

The antenna in the above scheme can be installed easily in any remote rural environment and operates as a separate independent system:

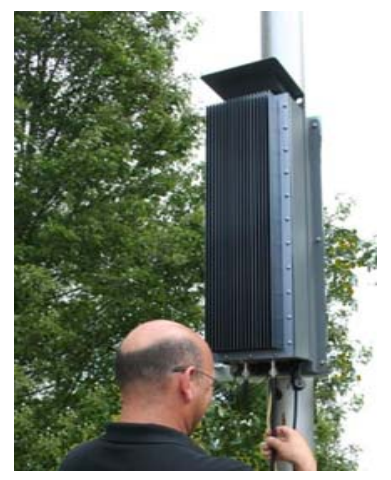

Source: Photo provided by Cofereral Network Inc., 2016.

The other features of the system include:

- Support LTE phones and SIP phones.

- Concurrent Rings

- One to many calls

- Mobile to mobile SMS

- One to many SMS

- PTT (Push-to-talk) calls

- Dispatch console for user status 
- Dispatch console for SMS broadcast

- Dispatch console for group calls

- Tx Power: 5-10W

- Interface: IP Network (Ethernet)

- Power Input: AC and DC Options Available

The cost of the LTE-based RAN is $\$ 45,000$, not including the costs of solar power supply, satellite terminal (if it needs to communicate with other telephone networks), LTE terminals/WiFi terminals and the services cost.

The cost today on putting a usable system together is considerably lowered now. More than 15 years ago, a low-cost station with a transmitting power of up to 50W that reaches a target audience of 5-10 square kilometers would cost between Rs 1 to 1.2 million (almost US\$ .5 million) (Frederick, 1998). The cost of putting a radio program together is not added to the above estimate. Basic equipment for recording, mixing, editing, and a 20-feet high antenna can increase cost a little more. Also, if radio programs can be syndicated, the cost of running a radio channel would not add too much to the social experiment.

Also, a key component of costs that need to be considered should include the budget of the ground operator NGO's proposal. The details on various components of costs can be estimated when suitable NGOs can be identified, along with the parameters specified in the following section.

\section{$5 \quad$ Other Strategies for Further Development of Smart Village}

Indian peasants can be the key propagators of Indian economy via agriculture activities. Mental health issue in the proposed experiment is only a lead. There can be a more comprehensive development of rural communities once the farmers are accustomed to wireless technology as their companions. Promoting psychiatric health of Indian farmers is a unique angle towards building a smart village. Once a psychological barrier on embracing technologies has been conquered, one can build towards a community rich in good health and spirit of Indian peasants. Embedding wireless technology therefore is not only a technical step, but also a psychological step that will ensure ultimately that farmers are facilitated with all sophisticated utilities in order to lead a hygienic lifestyle. An integrated approach further safeguards their health, security \& keeps them updated on the recent techniques in farming.

A schematic diagram retrieved on the internet shows a variety of development paths associated with the broad objective of promoting rural life (http://www.fao.org/docrep/w5830e/w5830e09.htm). One can use that as a guide on how wireless technology can extend quality of rural lifestyle once the farmers overcome a psychological barrier and start perceiving receiving additional information as a means to improve their quality of life.

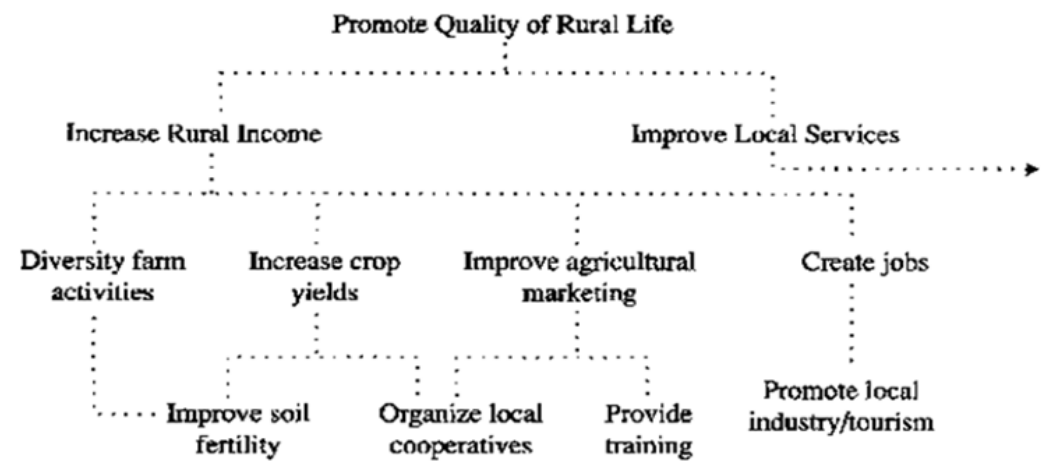

Source: http://www.fao.org/docrep/w5830e/w5830e09.htm

Quality of life plays an increasingly crucial role in shaping the economic growth of a country and boosts up a strong community (Bloom et al., 2001). Having access to basic amenities and novice facilities are stepping stone for leading a sophisticated life. Few scalable initiatives embedding wireless technology could be adopted for renaissance of quality of life among rural communities (Galperin, 2005). 
The concept of rural development could be enhanced by encompassing few innovations equipped with wireless technology, to improvise rural health and nutrition, creating a sustainable and environmentally safe place to thrive in, generating employment, imparting training in local communities on crop cultivation and soil health. In a nutshell, these initiatives when incorporated in rural India will aid in enhancing the quality of rural lifestyle and accrue more productivity among Indian peasants.

The followings are several specific innovations which could be further expanded in rural India when a remote village embraces wireless technologies:

1. Farmer's Call centre- Setting up of "Farmer Communities" in rural villages and providing them with the quick resolutions on the crop cultivation techniques, weather related information, and other issues raised by the Farmers could be an enticing initiative. For example, the National Agricultural Advisory Services (NAADS) has provided an experiment on how that can be done in Uganda. Communication is the integral element of such a strategy, adhering regional language could be an important step for implementation. Apart from the radio program proposed, every farmer in the community chosen to conduct this experiment could be given an access code/password to record and get answers to their individual farming concerns. This would help the farmers to manage a range of lifestyle related issues and a better way to manage their risks. As a complementary feature added to the radio facility, few toll-free numbers can be created for the farmers, which will connect them to various agricultural experts across the globe, who could suitably answer their concerns and also guide them on farming/irrigation techniques. The farmer's call centre is a meeting point for farmers, private organizations dealing with farm related activities, NGOs and civil society and basically tasked with receiving, registering, processing and providing instant feedback on various agricultural value chains and farmers complaints. All these can further build on the concept of Kisan Call Centres (KCC) in rural India (Kaushal, 2015). Incorporating mobile/Wireless application to advertise for other smart village initiatives in place, e.g. Digital Green dissemination of new farming methods, may also be considered.

2. Social Media Agriculture Community-Hub-In the fast technology moving era, we should not underestimate the power of internet. Social-media groups can be an added catalyst for accelerating farmers' life changing pathway and productivity. (See case studies of these in Technical Centre for Agricultural and Rural Cooperation, ACP (EU) CTA). Students/NGOs/Agricultural Experts/Social activists can come forward and take an initiative to volunteer in rural villages in India and create separate social media groups in rural communities. Furthermore, they can be monitored, as well as forming a bridge to collect information and solution techniques and expert answers from across the globe. This will speed up technology transfer to the farmers and would also aid in resolving location-specific agricultural based problems. Information on best fertilizers and pesticides to be used and also regarding their prices in local market could be communicated (Daily News Analysis, July 3, 2016.) The farmers will be connected directly to the market dealer who supplies/sells these manures and other agriculture related equipments and products. Undoubtedly, social-awareness among farmers will be enhanced by the development of the hub.

3. M-agricultural apps- Mobile apps could play a crucial role in shaping the future of Indian agriculture today. Apart from various deliverables to the farmers, m-agriculture app is a novice and efficient technology which will ensure the improvement in quality of rural life (Tali, 2015). Features like "m-financing" could help the farmer to get agricultural insurance coverage in case of natural calamities, where the agriculture sector is more vulnerable to destruction. Many government and also non-profit bodies which are financing rural farmers could register in the apps and provide timely help to the farmers. These mobile applications for agriculture and rural development also improve the agricultural supply chain management and add value to it. It leverages the economy of these developing countries and fosters more employments. Land, water, environment being the key elements of agriculture; these resources can also be managed by harnessing these apps. SMS alerts/weather alerts and other agriculture information can be received by the farmers (Qiang et.al, 2011) 
4. Creating an Online Market for farmers- The Online Market has been expected to make demand and supply operate more smoothly in India (Srivastava, 2008). Indian govt. has taken this initiative of promoting online markets for farmers. We could in turn empower this initiative and materialize it in almost all the agro-based states in India. This could also be implemented in other countries too as a development strategy in the agriculture sector. These online markets are created exclusively for the rural farmers where they could directly sell their products at the suitable market price which could ensure lot of transparency in the pricing strategy. Few Ngo and other industries could take up this initiative to connect them with this online market platform. Commodities and farm products which are location specific could be sold through this channel effectively and efficiently. Establishing an Online Market will reduce the transaction costs; providing single license valid across all the markets and also maintain the quality standard of products, as it would be directly sold by certified farmers.

5. Soil health- Ensuring good health of soil is a pre-requisite for sustainable land management. It is also vital for the proper functioning of the eco-system. High soil quality is a requisite for high productivity of the agricultural land. India has an agrarian economy and hence maintaining the biotic component of the Indian soil is essential to ensure high crop productivity. Fertilizers and pesticides; also a biotic (non-living) and biotic (living components) could be harnessed in the process to improve soil quality. Sustainable land management could be attained with this practice of translating science into practice. The Indian peasants could be given a platform to connect and communicate with pedologists across the globe. Timely awareness could be spread by various agriculture volunteers and NGOs. Information regarding varieties of crops suited to the weather condition and particular soil type of the areas could be studied by the expert department to impart more knowledge to the farmers and ensure high productivity.

6. Application of wireless remote sensing technology- Like human beings, even plants emit signals, during stressful soil conditions, using simple sensors (or) wireless sensor circuits (simple electrical optical circuit) which could transmit signal from the plants and the agriculture field timely. We could track the plant health and also foresee the yield potential in every season. This will not only increase the productivity of the crops but also pave a secured pathway for the farmers. The farmers could be provided with a "simple sensor circuit device" encased to make it handy and they could be informed and educated regarding the soil/plant health and crop productivity.

7. Rain Water harvesting- 'Rain Water harvesting' is the method of collecting and accumulating and depositing rain water from rooftops, rivers, etc. for re-use without allowing it to run-off. An artificial system could be set-up to store the rain water. "Ground water Recharge" could be done by this method, where the rain water is securely transferred to the ground water and it gets recharged. This method is the cheap and reliable method for arid climatic regions and drought affected lands.

These are some of the innovations that can be included when the social experiment suggested in this paper has demonstrated its effectiveness. Generally, fostering entrepreneurship in rural villages, capturing more value in the agriculture chain, building resilient community structures in rural areas of India will enhance the lifestyle of Indian peasants, paving the way for a better future.

\section{Conclusion}

This paper proposes a wireless network solution specifically for probing into farmers' suicide problems in India. By addressing their psychological needs and the urgency of needing human intervention at the moment of suicide decision, the use of a wireless device for communication is essential. The idea is people needs to get accustomed to a technological first, then dial in when they are in a critical stage when they need help. At a critical stage of suicide decision, no texting or any other long term solutions can help. A wireless network aiming at a remote rural village is also ideal for conducting social experiments utilizing an expert consulting platform. The setup of this platform can potentially achieve 
incentive compatibility with NGOs seeking funding from the West, which also have research agendas on methods of telepyschiatric treatments. With appropriate recruitment of partnership in the forming of an NGO alliance, the resulting NGO could make villagers in India generally smarter, achieving leapfrogging, and promoting sustainable development for India

Acknowledgements. This paper grew out of a practicum a group of MBA students did for Confederal Networks Inc. in the summer of 2016. It is structured as a fact-based proposal rather than an empirical study of hypothesis testing. We acknowledge the comments provided by the referee of his journal, and a NYIT 2016 GFSRC Summer grant support for this project.

\section{References}

1. Barua, Ankur. 2009. "Need for a Realistic Mental Health Programme in India." Indian Journal of Psychological Medicine. 31(1): 48-49.

2. Bloom, E.David; Craig,H.Patricia; Malaney,N.Pia.2001. "The Quality Of Life in Rural Asia.” Asian Development Bank. 2001

3. Booth, Nicholas; Martin Briscoe; Roy Powell. 2000. "Suicide in the farming community: methods used and contact with health services." Occupational and Environmental Medicine. 57:642-644

4. Carbonell, Isabelle M. 2016. "The ethics of big data in big agriculture." Internet Policy Review, 5(1). DOI: 10.14763/2016.1.405

5. Chapman, Robert; Roger Blench; Gordana Kranjac-Berisavljevic and A.B.T. Zakariah. 2003. "Rural Radio in Agricultural Extension: the Example of Vernacular Radio Programmes on Soil and Water Conservation in N. Ghana”. Agricultural Research \& Extension Network(AgREN), Network Paper No. 127.

6. Ciolos, Dacian; Piebalgs, Andris. 2012. Sustainable agriculture for the future we want. European Commission, European Union.

7. Cook, Seth. 2015. "Sustainable Agriculture in China: then and now." International Institute for Environment and Development Publication.

8. Das, T.K., and B.S. Teng. 1998. "Between trust and control: Developing confidence in partner cooperation in alliances." Academy of Management Review, 23 (3): 491-512.

9. Evans, Jonathan; Narasimhan, Meera. 2016. "Telepsychiatry: Enhancing Access to Mental Health Care." A PsychU presentation, August 2016.

10.Fässberg MM, van Orden KA, Duberstein P, Erlangsen A, Lapierre S, Bodner E, Canetto SS, De Leo D, Szanto K, Waern M. "A systematic review of social factors and suicidal behavior in older adulthood."

11.International journal of environmental research and public health. 2012 Mar; 9(3):722-45. Epub 2012 Mar 01.

12.Ferroni, Marco, and Yuan Zhou, 2012. "Achievements and Challenges in Agriculture Extension in India." Global Journal of Emerging Market Economies. 4(3): 319-346

13.Frederick, Noronha, 1998. "Community Radio in India."Cultural Survival, https://www.culturalsurvival.org/ publications/cultural-survival-quarterly/india/community-radio-india

14.Galperin, Hernan. 2005. "Wireless Networks and Rural Development: Opportunities for Latin America." Information Technologies and International Development, 2(3):47-56.

15.Gandhi, Rikin; Veeraraghavan, Rajesh; Toyoma, Kentaro; Ramprasad, Vanaja. 2009. "Digital Green: Participatory video and Mediated Instruction for Agricultural Extension." Information Technologies and International Development 5(1): 1-15

16.Godleski, Linda; Nieves, J. Edwin; Darkins, Adam; Lehmann, Laurent. 2008. "VA Telemental Health: Suicide Assessment." Behavioral Sciences \& the Law 26(3): 271-86.

17.Goli, Mohan K., Maddipatla, K., Sravani, T. 2011. "Integration of Wireless technologies for sustainable development." International Journal of Computer Science \& Technology, 2(4): 2229-4333.

18.Hoffman, Julia E. 2015. "Mobile Mental Health: Is There an App for That?" Webcast sponsored by PsychU.

19.Hollis, Chris; Richard Morriss, Jennifer Martin, Sarah Amani, Rebecca Cotton, Mike Denis, Shon Lewis. 2015.

"Technological innovations in mental health care: harnessing the digital revolution". The British Journal of Psychiatry. 206(4): 263-265.

20.Joiner, T.E. 2005. Why people die by suicide. Cambridge, MA: Harvard University Press. 
21.Kaushal, Akshat. 2015. "How Kisan Call Centres work." Business Standard, June 20, 2015. http://www.business-standard.com/article/current-affairs/how-kisan-call-centres-work-115062000022_1.html

22.Kinkade, Sheila; Verclas, Katrin. 2008. Wireless Technology for Social Change. Washington, DC and Berkshire, UK: UN foundation-Vodafone Group Foundation Partnership. Retrieved from http://www.globalproblemsglobalsolutions-files.org/unf_website/PDF/wireless_tech_social_change_trends_in_mobile\%20use.pdf.

23.Kleespies PM, Van Orden, KA; Bongar, B; Bridgeman, D; Bufka, LF; Galper, DI; Hillbrand, M; Yufit, RI. 2011. "Psychologist suicide: Incidence, impact, and suggestions for prevention, intervention, and postvention." Professional Psychology: Research and Practice, 42(3): 244-251.

24.Lorne, Frank; Shah, Sneh. 2015. "Price Reversal Pattern of ARV Drugs: A Transaction-Cost Approach Digression." Expert Journal of Economics. 3(2): 93-112.

25.Mallapur, Chaitanya, 2016. "9 Farmers Commit Suicide Daily In Drought-Hit Maharashtra."India Spend, August 09, 2016, https://www.indiaspend.com/cover-story/9-farmers-commit-suicide-dily-in-drought-hit-maharashtra41797

26.Mane, S. 2013. History of Radio in India. http://www.slideshare.net/sonalmane5/history-of-radio-in-india

27.Marasinghe, R.B., Eddirippulige, S., Kavanagh, D., Smith, A., \& Jiffry, M.T. (2012). "Effect Of mobile phonebased psychotherapy in suicide prevention: A randomized controlled trial in Sri-Lanka."JournalOf Telemedicine and Telecare, 18(3), 151-155. doi:10.1258/jtt.2012.sft107

28.McCarthy, John F.; Blow, Frederic C.; Ignacio, Rosalinda V.; Iigen, Mark A.; Austin, Karen L.; Valenstein, Marcia. 2012. "Suicide Among Patients in the Veteran Affairs Health System: Rural-Urban Differences in Rates, Risks, and Methods." American Journal of Public Health. 102(Suppl 1): S111-S117.

29.Meghna., August 19, 2010. "10 Measures to tackle the issue of farmers suicide in India." Legal Drift. http://www.legaldrift.com/10-measures-to-tackle-the-issue-of-farmer-suicides-in-india/

30.Mishra, Srijit, 2007. "Risks, Farmers' Suicides and Agrarian Crisis in India: Is There A Way Out?" Indira Gandhi Institute of Development Research (IGIDR).

31.Mishra,Srijit, 2014. Farmers' Suicides in India, 1995-2012: Measurement and interpretation.London School of Economics, Asia Research Centre, Working Paper 62.

32.Murphy, George E., 1983, "On Suicide Prediction and Prevention" Arch Gen Psychiatry. 40(3):343-344.

33.Orffman, A. and M. Schlessenger. 1997. "Trust, repute and the role of the non profit enterprise." Voluntas: Journal of Voluntary and non-profit organizations. 8:97.

34.Peterson, Douglas K. 2010. "Agency Perspectives on Ngo Governance." Journal of Management Research. Vol.2, No. 2.

35.Qiang, Zhenwei Christine; Kuek, Chew Siou; Dymond, Andrew; Esselaar, Steve. 2011. Mobile Applications for Agriculture and Rural Development. ICT Sector Unit, World Bank.

36.Radhakrishnan, Rajiv, and Chittaranjan Andrade. 2012. "Suicide: An Indian perspective". Indian Journal of Psychiatry. 2012 Oct-Dec; 54(4): 304-319.

37.Rukmini, S. 2015. "India's new farm suicides data: myths and facts." The Hindu, July 24.

38.Shiva, Vandana and Kunwar Jalees, Farmers Suicides in India, Research Foundation for Science, Technology and Ecology (New Delhi, India, 200x)

39.Srivastava,R.K.2008. "Changing retail scene in India." International Journal of Retail \& Distribution Management. 36(9):714-721

40.Stone, Glenn Davis. 2007. "Agricultural Deskilling and the Spread of Genetically Modified Cotton in Warangal". Current Anthropology. 48: 67-103.

41.Tali, Didem. 2015. "India's Rural Farmers struggle to Read and Write. Here's How "AgriApps" Might Change That." Project Literacy, Sept. 15, 2015. https://www.good.is/articles/agricultural-apps-bridge-literacy-gaps-inindia

42.Ugweje, O.C. 2004. Radio Frequency and Wireless Communications. The Internet Encyclopedia.

43.Vo, Alexander, Brooks, B.G., Farr, R., Raimer, B. Benefits of Telemedicine in remote communities \& use of mobile and wireless platforms in healthcare.University Of Texas Medical Branch (UTMB), Telemedicine and Center for Telehealth Research and Policy.(n.d.) Retrieved from: https://telehealth.utmb.edu/presentations/ Benefits_Of_Telemedicine.pdf

44.Yanacopulos, H. 2005. "The strategies that bind: NGO coalitions and their influence." Global Networks. 5(1): 93110. 
45.Amma, M.A.M. Mata Amritanandamayi Devi.--Farmers suicide Archives-(n.d.). http://www.amritapuri.org/ on/fm-suicide

46.Auroville International (AVI).(n.d.). Retrieved August 09, 2016, from http://www.auroville.org/contents/185 The Digital Green story 2016. https://www.youtube.com/watch?v=JYkaf4ucaSc

47.E-health Conference, July 31st, 2014, "Developing a Telemedicine service in a specialized mental health care organization" Retrieved from: http://www.e-healthconference.com/pastpresentations/2015/201462186071/ Vancouver_meeting_2014_final_version_Compatibility_Mode.pdf

48.BBC News, May 24, 2015, "What makes Indian farmers kill themselves." http://www.bbc.com/news/business32827047

49.Daily News Analysis, July 3, 2016. "Farmers $\log$ on to social media to maximise sales." Global Communities.http://www.globalcommunities.org/node/38087

50.Indian Express, May 24, 2016, "Marathwada: 36 farmers end life in a week" http://indianexpress.com/ article/india/india-news-india/marathwada-drought-farmers-suicide-drought-36-end-life-in-a-week-2815987/

51.Indiatimes. The Times of India, July 25, 2015, "Tiwari to head panel to curb farm distress". https://timesofindia.indiatimes.com/city/nagpur/Tiwari-to-head-panel-to-curb-farm-distress/articleshow/ 48208959.cms?

52.Milaap.org. July 26, 2015. Fundraising to help the victims of the farmer suicides in rural Maharashtra and provide rehabilitation facilities to their families. https://milaap.org/campaigns/help-the-vidarbha-farmers

53.Mid.Day. April 6, 2016. "Farmer suicides averaged 9 a day in 2015 in parched Maharashtra."

54.National Agricultural Advisory Services, NAAD. Retrieved from: http://www.naads.or.ug/data/sdmenu/41/ National\%20Farmer\%20Call\%20Centre.html

55.National Research Council, 2010. Toward Sustainable Agriculture Systems in the 21st Century. (Washington D.C.: National Academies Press).

56.NewsGram News Desk, july 5, 2015, "The farmer question : 6 main problems of Indian agriculture and 9 solutions to fix them"http://www.newsgram.com/the-farmer-question-6-main-problems-of-indian-agriculture-and9-solutions-to-fix-them/

57.Online Therapy User- Suicide Resources.(n.d.). https://www.onlinetherapyuser.ca/client-resources/suicideresources/

58.Technical Centre for Agricultural and Rural Cooperation, ACP(EU) CTA, 2015. Embracing Web 2.0 and Social Media.

59.The Atlantic, April 22, 2016. "The Diseases You Only Get if You Believe in Them", Julie Beck interview with Frank Bures.

60.The Economic Times, Dec 31, 2010, "Private FM Radio Players bet big on rural India". http://articles.economictimes.indiatimes.com/2010-12-31/news/27574549_1_private-fm-radio-radio-mirchiprashant-panday

61.The Hindu, June 10, 2016, "Small is Smart for this A.P. Village." http://www.thehindu.com/news/ national/andhra-pradesh/small-is-smart-for-this-ap-village/article8748970.ece

62.The New India Express, April 6, 2016. "Farmer Suicides Averaged 9 a Day in Parched Maharashtra" http://www.newindianexpress.com/nation/Farmer-Suicides-Averaged-9-a-Day-in-Parched-Maharashtra/2016/04/ 06/article3366563.ece

63. Vodafone Group Plc.2015. Connected Farming in India: How mobile can support farmers' livelihoods. An online publication. 